\title{
THE VISUAL PIGMENTS OF SOME DEEP-SEA ELASMOBRANCHS
}

\author{
By E. J. Denton and T. I. Shaw \\ The Plymouth Laboratory
}

$$
\text { (Text-figs. I-4) }
$$

The deep-sea teleosts have golden-coloured retinae, the photosensitive pigments of which absorb maximally at wavelengths close to the band of wavelengths around $475 \mathrm{~m} \mu$ to which the oceans are most transparent (Denton \& Warren, I956, I957; Munz, I957, I958a; Wald, Brown \& Brown, I957). In this they differ from freshwater fish, which usually have purple-coloured retinae absorbing maximally at wavelengths around $525 \mathrm{~m} \mu$, and marine coastal fish, which usually, but not always, have reddish-coloured retinae absorbing maximally at wavelengths close to $500 \mathrm{~m} \mu$ (Wald, I945-46; Dartnall, I952; Munz, I958b). This communication extends these studies to include three species of deep-sea elasmobranchs, using the classical method of making digitonin extracts.

With a little experience it is easy to estimate from the colours of freshly dissected retinae of dark-adapted animals the approximate wavelengths of maximum absorption of their retinal pigments. When interesting animals have been available on occasions when we could not make a detailed study of the retinal pigments, we have, therefore, examined their retinae also, comparing them with retinae from animals such as the frog and the conger eel, whose retinae have been very well studied. Here we describe observations of this kind made on the salmon and the Moray eel.

\section{MATERIALS}

The deep-sea sharks, Centroscymmus coelolepis Bocage \& Capello, Centrophorus squamosus Bonnaterre and Deania calcea Lowe, were caught at a depth of $\mathrm{I}, \mathrm{I} 50 \mathrm{~m}$ at $47^{\circ} 4 \mathrm{I} \cdot 5^{\prime} \mathrm{N} ., 7^{\circ} 36^{\prime} \mathrm{W}$. They were caught at night in May using a deep-sea line. The hake, Merluccius merluccius (L.), were caught at night by trawl 2I miles south of the Wolf rock in the English channel. Moray eels, Muraena helena L., were supplied by fishermen working off Monaco.

\section{METHODS}

Preparation of retinae. The sharks and hake were caught at night and kept alive in a darkened sea-water tank for a few hours until their eyes were dissected. Moray eels were dark-adapted in a tank of sea water for several hours before their eyes were removed. 


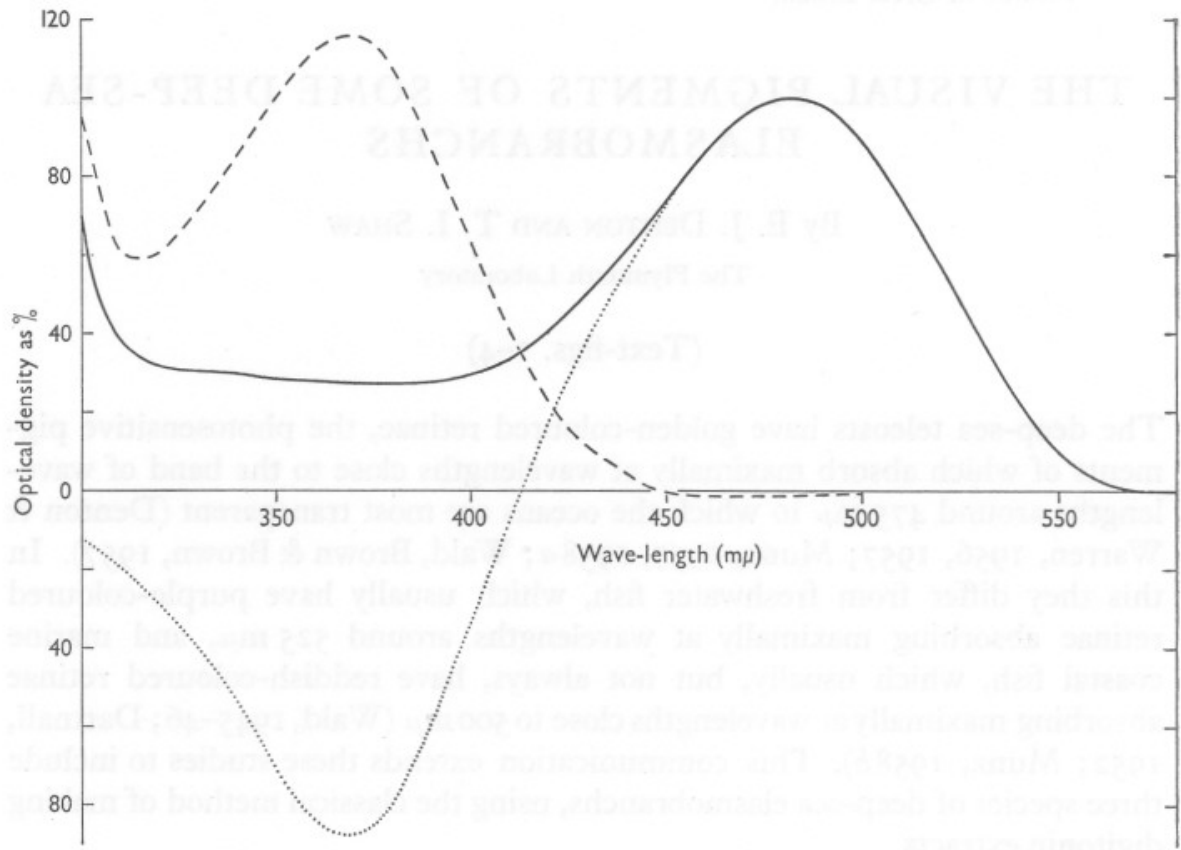

Fig. I. Absorption spectrum of retinal extract from Centrophorus squamosus: -, unbleached extract; ---, bleached extract; ....., difference curve. Data for the bleached and unbleached forms are plotted as percentage absorption of the unbleached material at $482 \mathrm{~m} \mu(E=0.13 \mathrm{I})$. The difference curve is plotted as percentage of difference at the same wavelength. The extract was prepared from 2 retinae in $3 \mathrm{ml}$. of solution.

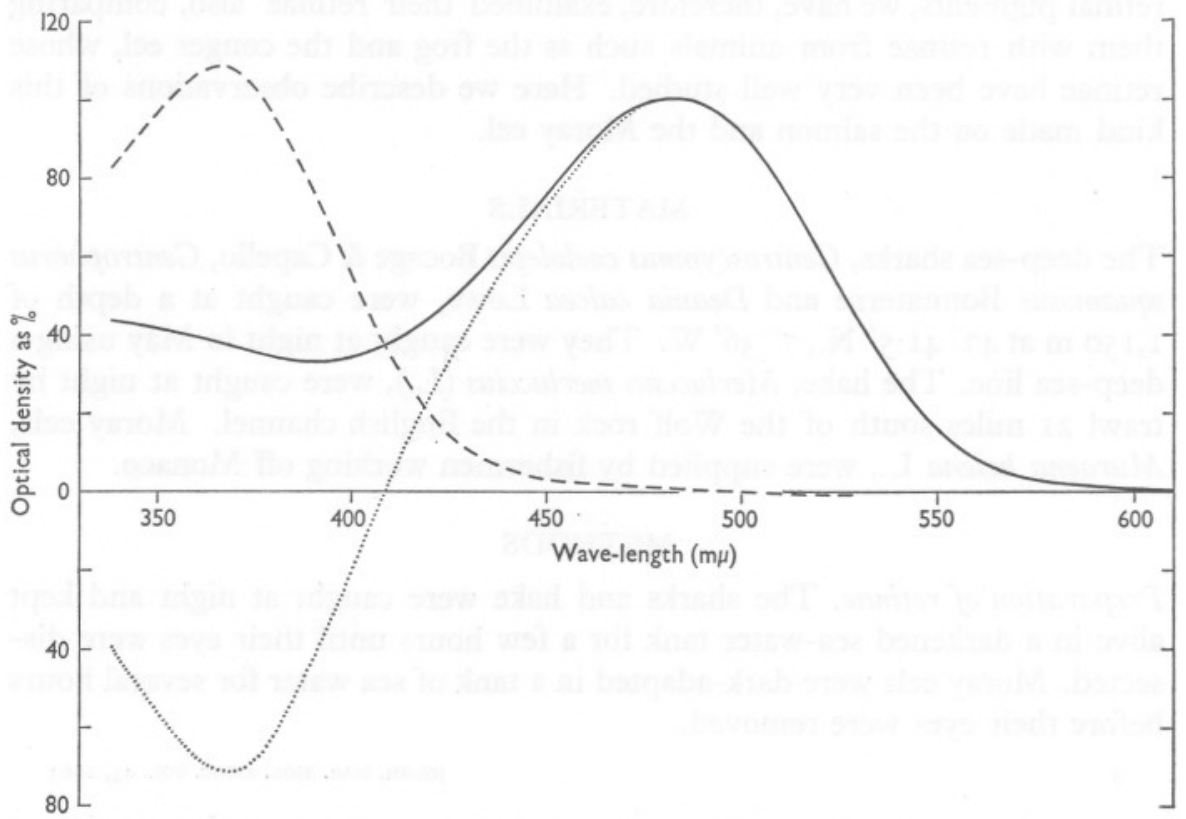

Fig. 2. Absorption spectrum, as in Fig. I, of retinal extract from Deania calcea. Curves for the bleached and unbleached extract are plotted as percentage of absorption of the unbleached material at $484 \mathrm{~m} \mu(E=0.237)$. 


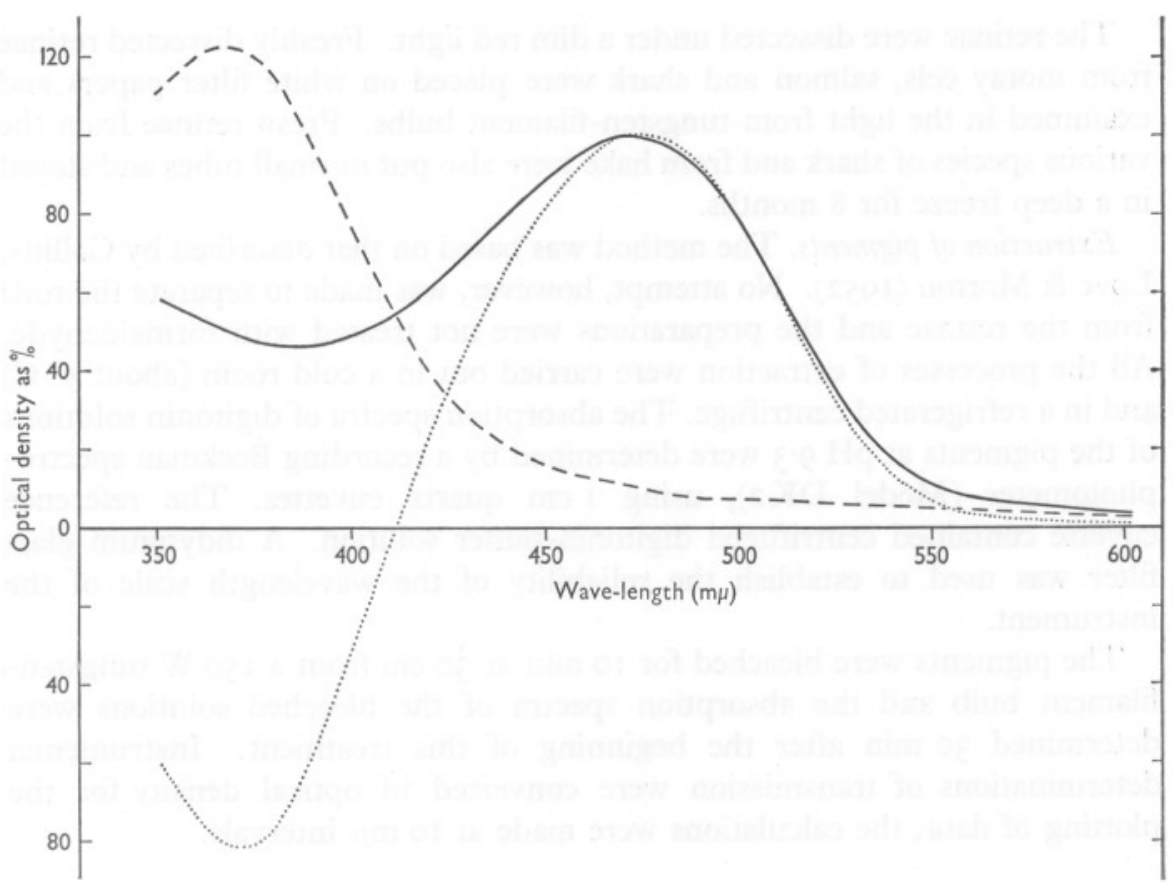

Fig. 3. Absorption spectrum, as in Fig. I, of retinal extract from Centroscymnus coelolepis. Data for the bleached and unbleached forms are plotted as percentage absorption of the unbleached material at $472 \mathrm{~m} \mu(E=0.253)$.

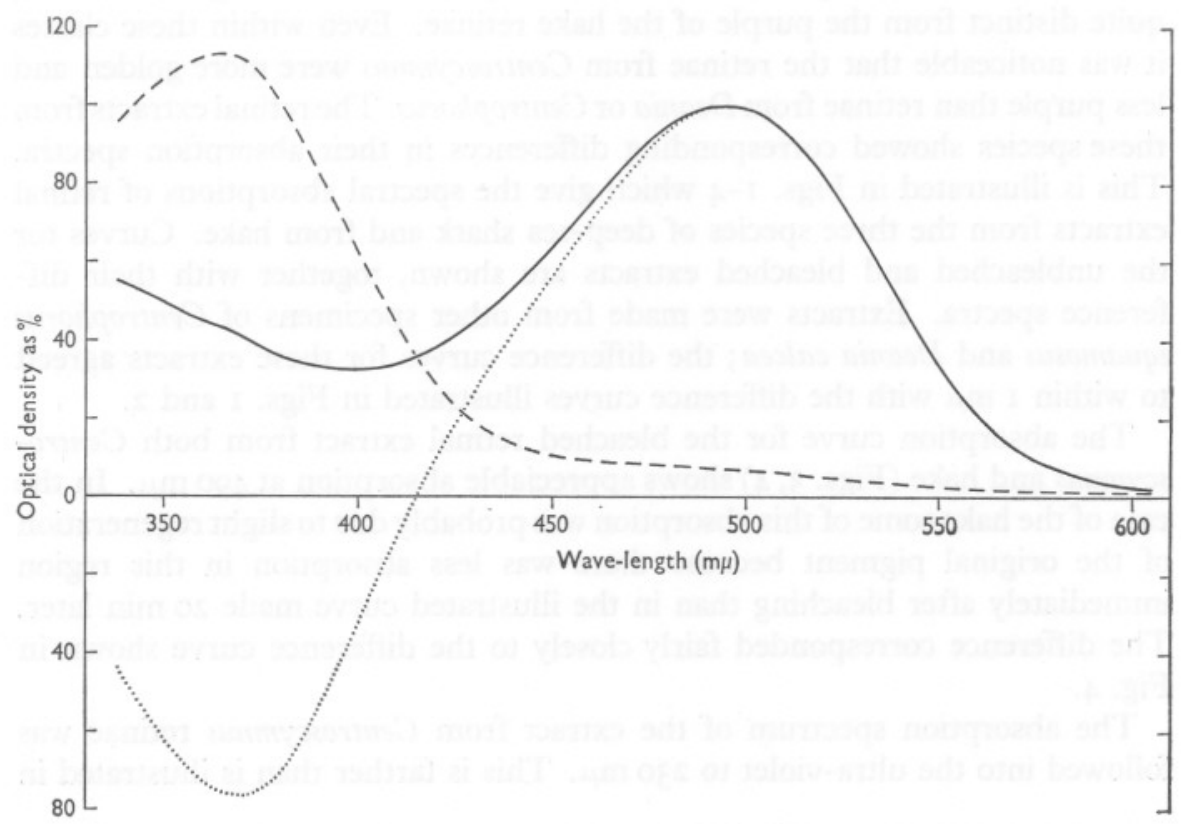

Fig. 4. Absorption spectrum, as in Fig. I, of retinal extract from hake (Merluccius merluccius). Data for the bleached and unbleached forms are plotted as percentage absorption of the unbleached material at $496 \mathrm{~m} \mu(E=0.7 \mathrm{I})$. 
The retinae were dissected under a dim red light. Freshly dissected retinae from moray eels, salmon and shark were placed on white filter papers and examined in the light from tungsten-filament bulbs. Fresh retinae from the various species of shark and from hake were also put in small tubes and stored in a deep freeze for 8 months.

Extraction of pigments. The method was based on that described by Collins, Love \& Morton (I952). No attempt, however, was made to separate the rods from the retinae and the preparations were not treated with formaldehyde. All the processes of extraction were carried out in a cold room (about $5^{\circ} \mathrm{C}$ ) and in a refrigerated centrifuge. The absorption spectra of digitonin solutions of the pigments at $\mathrm{pH} 9.3$ were determined by a recording Beckman spectrophotometer (Model DK2), using I cm quartz cuvettes. The reference cuvette contained centrifuged digitonin-buffer solution. A didymium glass filter was used to establish the reliability of the wavelength scale of the instrument.

The pigments were bleached for IO $\mathrm{min}$ at $30 \mathrm{~cm}$ from a $\mathrm{I} 50 \mathrm{~W}$ tungstenfilament bulb and the absorption spectra of the bleached solutions were determined $30 \mathrm{~min}$ after the beginning of this treatment. Instrumental determinations of transmission were converted to optical density for the plotting of data; the calculations were made at $\operatorname{ro~} \mathrm{m} \mu$ intervals.

\section{RESULTS}

The retinae of the deep-sea sharks and moray eels were a rich golden colour, quite distinct from the purple of the hake retinae. Even within these classes it was noticeable that the retinae from Centroscymnus were more golden and less purple than retinae from Deania or Centrophorus. The retinal extracts from these species showed corresponding differences in their absorption spectra. This is illustrated in Figs. I-4 which give the spectral absorptions of retinal extracts from the three species of deep-sea shark and from hake. Curves for the unbleached and bleached extracts are shown, together with their difference spectra. Extracts were made from other specimens of Centrophorus squamosus and Deania calcea; the difference curves for these extracts agreed to within I $\mathrm{m} \mu$ with the difference curves illustrated in Figs. I and 2.

The absorption curve for the bleached retinal extract from both Centroscymnus and hake (Figs. 3, 4) shows appreciable absorption at $490 \mathrm{~m} \mu$. In the case of the hake some of this absorption was probably due to slight regeneration of the original pigment because there was less absorption in this region immediately after bleaching than in the illustrated curve made 20 min later. The difference corresponded fairly closely to the difference curve shown in Fig. 4.

The absorption spectrum of the extract from Centroscymnus retinae was followed into the ultra-violet to $230 \mathrm{~m} \mu$. This is farther than is illustrated in 
Fig. I. There was a marked absorption maximum at $274 \mathrm{~m} \mu$, close to the wavelength at which preparations of rhodopsin show an absorption peak (Collins, Love \& Morton, I95I). For Centroscymnus extract the absorption at this peak was $67 \%$ of the absorption at the visible peak of the unbleached extract.

The purity of retinal extracts has been judged from their absorption at the trough near $400 \mathrm{~m} \mu$ relative to their absorption at the visible peak of the unbleached extract (Wald, I937-38). The purest rhodopsin preparations give ratios down to 0.205 (Collins et al., 1952) while the preparations illustrated in Figs. I-4 gave relative absorptions of 0.28 to 0.46 .

Some retinae were only examined visually. Salmon parr and salmon smolt were taken from rivers in Devon. With the very kind help of Dr P. F. Elson of the Fisheries Research Biological Station, St Andrews, N.B., Canada, the retinae from a salmon caught in the estuary of the Mirimachi River, on returning from the sea, and a salmon post smolt $(27 \mathrm{~cm}$ long) which had been kept in the laboratory in sea water for 2 months were examined at the St Andrews laboratory. All these fish had purple-coloured retinae typical of freshwater fish so that it seems unlikely that Salmo salar change their visual pigments during migration.

The colour of the moray eel's retina was between the gold of the conger eel Conger conger (see Denton \& Walker, I958) and the red of the frog Rana temporaria.

\section{DISCUSSION}

These results indicate that the visual pigments of deep-sea elasmobranchs are very similar to those of deep-sea teleosts. With respect to their visual pigments the deep-sea fishes form a very homogeneous group in that all have golden pigments absorbing maximally at wavelengths close to that to which the sea is most transparent.

Animals whose visual pigments change during the life cycle are particularly interesting. Thus Wald (1945-46) has shown that the tadpole of a bullfrog has a purple-coloured retina containing porphyropsin, a visual pigment whose chromophore group is derived from Vitamin $\mathrm{A}_{2}$, whilst the adult frog's retina contains the red-coloured rhodopsin whose chromophore is based on Vitamin $\mathrm{A}_{1}$. The lamprey Petromyzon marinus (see Wald, 1957) and the freshwater eel Anguilla anguilla both show changes which are associated with their migrations (Carlisle \& Denton, I959; Brown \& Brown, cited by Wald, I960), and such changes are very well discussed by Crescitelli (I958) and Wald (I960).

The results on the salmon show that there is little or no metamorphosis of the visual pigments on migration to and from the sea and certainly there is no indication of a change to the deep-sea form as is found in the freshwater eel: they suggest that the salmon remains in the surface waters of the ocean. 
We are indebted to Mr G. R. Forster for allowing us to use the deep-sea fishes caught on his long-line apparatus. The work at Monaco was assisted by a grant from the Browne Research Fund of the Royal Society.

\section{SUMMARY}

The retinae of three species of deep-sea shark, Centrophorus squamosus, Centroscymnus coelolepis and Deania calcea, have been studied. All had goldencoloured photosensitive pigments, similar to those of deep-sea teleosts. The absorption maxima for the unbleached pigments lay between 472 and $484 \mathrm{~m} \mu$. The retina of the hake (Merluccius merluccius) was studied for comparison; its retinal pigment absorbed maximally at $495.5 \mathrm{~m} \mu$. Some observations on the retinae of the moray eel (Muraena helena) and the Atlantic salmon (Salmo salar) are also described.

\section{REFERENCES}

Carlisle, D. B. \& Denton, E. J., I959. On the metamorphosis of the visual pigments of Anguilla anguilla (L.). F. mar. biol. Ass. U.K., Vol. 38, 97-102.

Collins, F. D., Love, R. M. \& Morton, R. A., I952. Studies in rhodopsin. 4. Preparation of rhodopsin. Biochem. F. Vol. 5I, pp. 292-8.

Crescitelli, F., I958. The natural history of visual pigments. Photobiology-the I9th Annual Biology Colloquium at Oregon State College, pp. 30-5I.

Dartnall, H. J. A. (I952). Visual pigment 467, a photosensitive pigment present in tench retinae. F. Physiol., Vol. I16, pp. 257-89.

Denton, E. J. \& MARY AnN WALKer, I958. The visual pigment of the conger eel. Proc. Roy. Soc. B, Vol. I48, pp. 257-69.

Denton, E. J. \& WARREN, F. J., I956. Visual pigments of deep sea fish. Nature, Lond., Vol. I78, p. 1059.

- 1957. The photosensitive pigments in the retinae of deep sea fish. F. mar. biol. Ass. U.K., Vol. 36, pp. 651-62.

MunZ, F. W., 1957. Photosentitive pigments from retinas of deep-sea fishes. Science, Vol. I25, pp. II $42-3$.

- 1958a. Photosensitive pigments in the retinae of certain deep-sea fishes. F. Physiol., Vol. 140, pp. 220-35.

- 1958 $\mathrm{b}$. The photosensitive pigments of fishes from relatively turbid coastal waters. F. gen. Physiol., Vol. 42, pp. 445-59.

WaLD, C., 1937-38. On rhodopsin in solution. F. gen. Physiol., Vol. 21, pp. 795-832.

Wald, G., I945-46. The chemical evolution of vision. Harvey Lect., Ser. 4I, pp. $117-70$.

— 1957. The metamorphosis of visual systems in the sea lamprey. F. gen. Physiol., Vol. 40, pp. 90I-I4.

- 1960. The significance of vertebrate metamorphosis. Circulation, Vol. 21, pp. 916-38.

Wald, G., Brown, P. K. \& Brown, P. S., I957. Visual pigments and depths of habitat of marine fishes. Nature, Lond., Vol. I80, pp. 969-7I. 